- Inequalities in health service use are also seen in dental service use by the aged.

- Disadvantaged aged are clearly not attending dental professionals.

- These disadvantaged groups need targeting before the impact of age restricts their access to treatment.

- Prevention is important in these groups - resource allocation is a dental priority.

- Dental care of older persons requires innovative long-term strategies.

\title{
The relationship between demographic and health-related factors on dental service attendance by older Australians
}

\author{
L. Slack-Smith ${ }^{1}$ and J. Hyndman ${ }^{2}$
}

\begin{abstract}
Objective To determine factors associated with dental attendance by those of 60 years or older in a population-based sample.

Design Cross-sectional national health survey.

Setting The study used data from the Australian 1995 National Health Survey, which consisted of people interviewed by households.

Subjects and Methods A total of 7,544 eligible respondents randomly selected by households from defined statistical areas.

Main outcome measures The main outcome investigated in this study was having had a dental visit in the previous 12 months.

Main results Age, income, level of social disadvantage, level of education, uptake of private health insurance, smoking, exercise, self assessment of health and having a health concession card all independently influenced the attendance ratios. In combination, after adjusting for all other factors, factors associated with having visited a dentist for males were age, years of schooling, level of social disadvantage, exercise level index, possession of a health concession card and smoking status. Factors associated with having visited for females were age, education, exercise, smoking status and some levels of the interaction between possession of a health concession card and level of social disadvantage.

Conclusions The strong influence of age, education, exercise and smoking status indicated a need to target dental services towards those elderly persons in low attendance groups, which mostly represented disadvantaged groups.
\end{abstract}

\section{INTRODUCTION}

The need to deal with the increasing demand for dental services in the aged and the need to move from emergency treatment to

Senior Lecturer, School of Population Health and Senior Lecturer in Oral Epidemiology, School of Dentistry, The University of Western Australia; ${ }^{2}$ Adjunct Research Fellow, School of Population Health, The University of Western Australia

Correspondence to: Dr Linda Slack-Smith, Senior Lecturer, School of Population Health M431 and Senior Lecturer in Oral Epidemiology, School of Dentistry, 35 Stirling Hwy, Nedlands, Perth, The University of Western Australia, Australia

Email:lindas@cyllene.uwa.edu.au

\section{Refereed Paper}

Received 17.06.02; Accepted 07.11.03

doi:10.1038/sj.bdj.4811571

( ) British Dental Journal 2004; 197: 193-199 prevention are relevant internationally. ${ }^{1}$ In the USA, the Surgeon General's report on oral health has identified the need for health services research in dental services and has also noted the disparities in use of services and outcomes in some population subgroups including the aged. ${ }^{2}$ Poor oral health in older persons can seriously affect their quality of life. ${ }^{3-6}$ A range of factors may be associated with the use of dental services in adults including age, sex, ethnicity, education level, health status, marital status, employment, socio-economic status, cost of service, uptake of dental insurance, health beliefs and dental anxiety., ${ }^{7,8}$ In a US study, Manski found age, sex and ethnic background to be associated with dental service use while health-related factors were not associated. ${ }^{9}$

In Australia, despite the fact that most oral diseases are preventable, the annual cost of dental treatment exceeds AUD\$1.8 billion (US $\$ 1.18$ billion, $€ 1.01$ billion at 23 May 2003). ${ }^{10}$ This cost is predominately for treatment rather than preventive services. Dental services for adults in Australia consist of an extensive private system with some state-based public dental care for those with healthcare cards (which are generally given to those receiving government assistance who have lower income). ${ }^{11}$ In Australia, as with overseas, the aged have been identified as being at risk of poor oral health. ${ }^{12,13}$ However, the demand for dental services in the aged exceeds public capacity and there is a subsequent emphasis on emergency treatment rather than preventive care. ${ }^{14}$ The increasing proportion of aged in the population and increasing retention of teeth in older persons will increase demand on dental services even further in this group..$^{9,13,15}$

It has been recognised that there is a need for detailed data regarding oral health in older Australians and their dental service needs. ${ }^{16}$ One of the few population-based published studies looked at broad factors associated with the use of dental services in those over 15 years in a previous 1989-90 National Health Survey in Australia. ${ }^{11}$ To improve dental services for the over 60s, a detailed understanding of why and how they use services is required. Many studies lack detailed consideration of variables of potential interest, and are not based on population data of adequate size. In addition, aggregate quantitative data often does not demonstrate the oral health needs of segments of society that are substantially disadvantaged. ${ }^{3}$ 


\section{RESEARCH}

This study investigated the differences between those aged 60 years or more, who have and have not had a dental visit in the previous year. Data were obtained from the Australian 1995 National Health Survey. ${ }^{17}$ The analysis was in two stages: initial descriptive statistics identifying factors associated with attendance at dental services in the previous 12 months and logistic regression analysis describing the influence and interrelationship between factors on the outcome of attendance or not at dental services in the previous year. The use of multivariable analysis in such investigation is supported. ${ }^{9}$

\section{METHODS}

This study used data made available from the Australian National Health Survey 1995. In the survey, the total unweighted response rate by households was 91.5\%. Questionnaires were obtained from $97 \%$ of the eligible people in these households. ${ }^{17}$ There were 7,602 respondents aged 60 years or over in the 1995 Australian National Health Survey sample. The outcome of interest for this study was having visited a dental professional in the previous 12 months. Of the 7,602 respondents, 58 did not know when they had last seen a dental professional and these cases were omitted from the analysis (leaving 7,544 eligible respondents).

Since every member of selected households was surveyed, there was the possibility of correlation between responses. However investigation of attendance behaviour between respondents in the same households showed no evidence of a bias resulting from related attendance behaviour $\left(\chi^{2}=3.36, P=0.066\right)$.

\section{Weights}

The Australian Bureau of Statistics provided a weight for each record in the 1995 National Health Survey. ${ }^{17}$ Weights were applied to the survey data to reflect the full Australian population. Application of the weights to the sample in the National Health Survey data resulted in a population of 2,835,198 people 60 years and over. This compared with the Australian 1996 Population Census count of 2,834,625 people in this age group. ${ }^{18}$

\section{Univariate analysis}

Characteristics of interest were considered for association with having visited a dental professional in the previous 12 months. These were considered in four groups: the relationship with the demographic variables of age, sex, education, ethnicity, income, level of social disadvantage and presence of another adult in the household; the relationship with elective and government sponsored insurance schemes; the relationship with smoking and exercise which are health behaviour variables; and the relationship with personal health factors including self assessment of health, the presence of arthritis and the use of pain relief medication for dental conditions.

\section{Demographic variables}

The variable 'age first left school' was the most appropriate measure of level of education for the purpose of this analysis. There is some evidence that some groups are more likely to attend dental care than other Australians, for example migrants over 65 years. ${ }^{19}$ One measure of ethnicity on the National Health Survey questionnaire was the usual language spoken at home. This was selected for use in the analysis as a more appropriate measure of retention of cultural behaviour than the other possible variable of country of birth, for which many individual categories were too small for meaningful interpretation.

Since dental services are not covered by the Australian universal medical insurance scheme (Medicare), some measure of wealth was required to clarify whether respondents did not attend the dentist because they could not afford it. The measure of income used in the analysis was the equivalent income decile. The Socio- economic Indices for Area (SEIFA) index of social disadvantage provided a measure of social disadvantage in the area the person lived. This was based on the attributes of the population within Collectors' Districts. These are the smallest area units used by the Australian Bureau of Statistics and contain about 250 dwellings each. ${ }^{20}$ Each response was therefore coded as belonging to one of five quintiles of social disadvantage according to the location of their residence.

It was also thought that the availability of personal support could influence attendance at dental services for the age group of respondents included in this study. A surrogate for level of personal support was derived using a field that indicated the presence of another adult in the household. However, it should be noted that there was no information available about the possible input from social support agencies.

\section{Health insurance variables}

A federal scheme supported dental care in needy adults from 1994 to 1996, but generally public dental care is provided by states to selected disadvantaged adults. ${ }^{11}$ Unless the patient is eligible for these subsidised dental services, they must pay the cost of private dental care.

Australians have to arrange for their own private health insurance if they wish to be reimbursed for their dental expenses. This insurance may be for ancillary benefits only (such as dental, glasses, physiotherapy, ambulance) or include hospitalisation cover. The National Health Survey collected information on private health insurance and whether that insurance covered ancillary benefits usually including dental cover.

Half of the respondents, who were allocated to the SF-36 (Short Form 36 health status questionnaire) survey subgroup of the 1995 National Health Survey using a General Health and Well-Being Form, were not asked the questions on health insurance. ${ }^{21}$ This was part of the original study design. ${ }^{17}$ of the remaining respondents, $43 \%$ had some private health insurance and of these $64 \%$ had ancillary cover that may or may not include dental insurance. In addition, 1.8\% did not know what type of insurance cover they had. Older people in Australia were more likely to be in receipt of a health concession card than younger compatriots.

\section{Health behaviour variables}

The National Health Survey conducted in 1995 provided data on the smoking status of respondents: smokers, ex-smokers and never smoked. As an indicator of a respondent's mobility the data item Exercise Level Index was used. The percentage of the elderly respondents in each category were: vigorous (2\%), moderate (26\%), low (30\%) and sedentary (42\%).

\section{Personal health variables}

Respondents were asked for their personal assessment of their health using the five categories of excellent, very good, good, fair and poor. The National Health Survey asked specific questions about presence of arthritis. In this paper the derived variable of the presence of arthritis (either osteo or rheumatoid) that was expected to last for more than 6 months, was related to the use of dental services in the previous year. The raw numbers indicated that $40 \%$ of those aged 60 years or more reported a long-term arthritic condition.

\section{Statistical tests}

The test for significance used for all of the univariate analysis was the $t$-test for differences in attendance ratios between variables that had two levels. The regression test for linear trend in attendance ratios was used for variables with more than two levels. 


\section{Multivariable analysis}

A logistic regression model was formulated to determine variables which were associated with attendance at dental services. The analysis was performed as a stepwise regression in SAS. ${ }^{21}$ Normalised population weights were applied to the sample frame in order to reflect the population profile. In order to obtain results most useful for public health intervention programmes, the multivariable analysis was undertaken for males and females separately.

\section{Variables with missing values or small responses}

Two of the variables used in the univariate analysis had high counts of missing values: decile of equivalent income had 17\% of responses with missing values, and private insurance status had $50 \%$ missing values where these questions were skipped for those respondents allocated the SF-36 sub sample. These two fields were omitted from the multivariable analysis, as inclusion would have eliminated more than $50 \%$ of the records.

There were only 17 affirmative sample responses to the use of pain medication for dental pain so the variable was excluded from the multivariable model.

Logistic regression model: The following interactions were tested for each of the two models (male and female):

- Age with: age, years at school, possession of a health concession card, self assessment of health, exercise level index, presence of another adult in the household and the SEIFA index quintile, and

- SEIFA index quintile with: possession of a health concession card and usual language spoken at home.

\section{RESULTS}

\section{Univariate analysis}

Table 1 shows the percentage of respondents who had attended a dental professional within the previous 12 months by the demographic variables of age, sex, education, ethnicity, income, social disadvantage and the presence of another adult in the household. Males were more likely to have attended dental services within the past 12 months than females $(36.3 \%$ versus $33.5 \% t$-value $=2.52$, $P=0.012$ ). Older respondents were less likely to have attended dental services in the past year. There was a marked trend over the 5 -year age groups with $40 \%$ of the 60-64-year-olds attending within the past year compared with $21 \%$ of those aged 80 years and over. Figure 1 shows the difference in the attendance proportion, for males and females, over age groups. The males had higher attendance ratios in the over 70-year-old age groups than females, and vice versa for the younger age groups.

The positive effect of a higher level of school eduction on recent dental attendance was significant. This variable showed a clear trend despite the age of the respondents. Our study showed that respondents who did not usually speak English at home had a significantly higher attendance ratio than those who spoke English at home.

The data clearly indicated the relationship between attendance at dental services and income. Respondents from less disadvantaged areas were more likely to attend dental services than those in disadvantaged areas. Figures 2 and 3 illustrate the consistently detrimental effect of living in socially disadvantaged areas, compared with least disadvantaged areas, on attendance at dental services irrespective of exercise level indices or levels of self assessment of health (see results for exercise levels and self assessment of health).

There was a significantly higher level of attendance at dental services for those who had another adult in the house. While this effect was significant for both males and females, the $P$ value was lower for males.

\section{Relationship with elective health insurance, health behaviour} and personal health factors

Respondents who were covered by ancillary health insurance (which would normally cover dental expenses) had significantly higher attendance ratios than those who did not (Table 2).

Those respondents who had a health concession card provided by the government were significantly less likely to have attended dental services in the previous year than those who did not. Investigation showed that those with a concession card were more likely to live in the most disadvantaged rather than least disadvantaged areas $(P<0.0001)$, to be in poor rather than excellent health $(P<$ $0.0001)$, not to have ancillary health insurance $(P<0.0001)$ and to have a lower level of schooling $(P<0.0001)$. All these associated factors contributed to the outcome of having a concession card and not attending dental services.

The attendance at dental services within the last year by smoking status showed that there was a significant difference in the attendance ratios between smokers and ex-smokers $(P<0.0001)$ and between smokers and never smoked $(P<0.0001)$.

Younger respondents, in the 60-64 years old age group, were more likely than older respondents to have attended dental services if they had never smoked. The results for the older respondents were more mixed, but those who were aged 70 years or more were more likely to have attended if they were ex-smokers.

Level of exercise was a strong determinant of attendance at dental services, with those who reported undertaking vigorous exercise more likely to attend dental services than those who reported sedentary levels of exercise. Figure 2 illustrates the effect of increasing attendance at dental services with higher levels of activity, as well as the strong association with level of social disadvantage.

Overall those who reported excellent or very good health were more likely to have attended dental services in the previous year, than those who reported that they thought that they had poor health. The trend in attendance ratio over the categories of selfassessment of health was significant. In addition, as shown in Figure 3, the attendance ratios differed markedly between those from most and least disadvantaged areas for every level of selfassessment of health.

There was no significant difference in attendance ratios between the respondents who had ongoing arthritis and those who did not have arthritis. However, further investigation showed significant differences in attendance ratios for males overall $(P=$ 0.048), for males in the age group of 65-69 years $(P=0.04)$ and the female age group of $80+$ years. In each of these groups the presence of arthritis increased the attendance ratio.

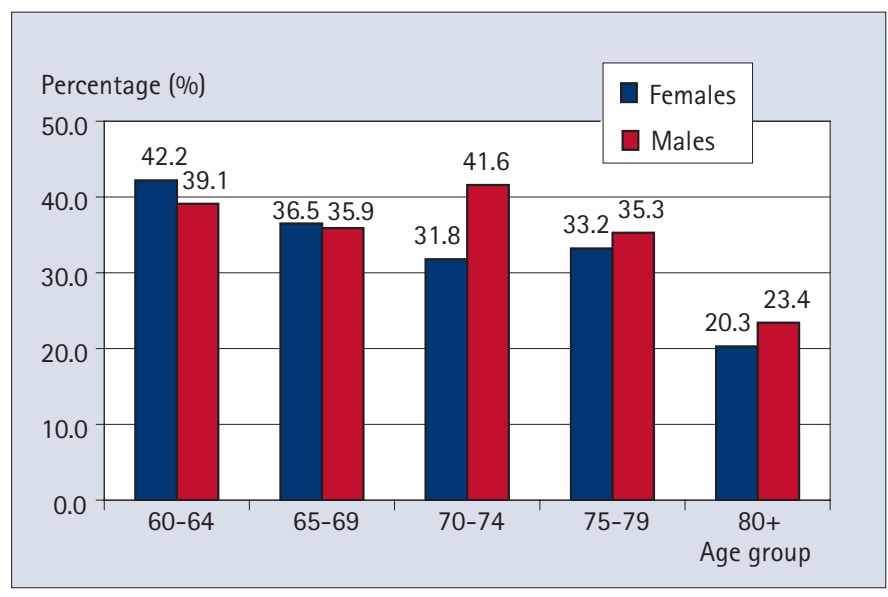

Fig. 1 Percentage of respondents within each age group who reported that they had seen a dentist or dental professional in the previous year (weighted data) 


\begin{tabular}{|c|c|c|c|c|c|c|c|}
\hline & $\begin{array}{c}\text { Number not } \\
\text { attending }\end{array}$ & $\begin{array}{l}\text { Number } \\
\text { attending }\end{array}$ & $\begin{array}{l}\text { Per cent } \\
\text { attending }\end{array}$ & & $\begin{array}{l}\text { Number not } \\
\text { attending }\end{array}$ & $\begin{array}{c}\text { Number } \\
\text { attending }\end{array}$ & $\begin{array}{l}\text { Per cent } \\
\text { attending }\end{array}$ \\
\hline \multirow[t]{2}{*}{ Total } & $1,850,322$ & 984,876 & 34.7 & \multicolumn{4}{|c|}{ Wealth (Equivalent income decile) (trend test, $P=0.0001$ ) } \\
\hline & & & & 10th (Highest income) & 80,090 & 41,926 & 60.2 \\
\hline \multicolumn{4}{|c|}{ Sex $(t$-test, $P=0.0118)$} & 9th & 332,360 & 107,399 & 52.2 \\
\hline Males & 813,603 & 462,884 & 36.3 & 8th & 402,418 & 151,126 & 46.6 \\
\hline \multirow[t]{2}{*}{ Females } & $1,036,720$ & 521,993 & 33.5 & 7th & 319,794 & 155,499 & 43.9 \\
\hline & & & & 6th & 160,394 & 83,242 & 44.1 \\
\hline \multicolumn{4}{|c|}{ Age (trend test, $P=0.0451$ ) } & 5 th & 84,764 & 66,887 & 34.2 \\
\hline $60-64$ & 415,856 & 282,286 & 40.4 & 4th & 65,977 & 51,581 & 32.7 \\
\hline $65-69$ & 439,156 & 247,701 & 36.1 & $3 \mathrm{rd}$ & 51,626 & 44,962 & 27.3 \\
\hline $70-74$ & 420,085 & 232,939 & 35.7 & 2nd & 32,421 & 35,416 & 24.4 \\
\hline $75-79$ & 276,622 & 141,754 & 33.9 & 1st (Lowest income) & 40,383 & 61,123 & 34.4 \\
\hline \multirow[t]{2}{*}{$80+$} & 298,603 & 80,196 & 21.2 & & & & \\
\hline & & & & \multicolumn{4}{|c|}{ Location level of disadvantage (SEIFA quintile) (trend test, $P=0.0339$ ) } \\
\hline \multicolumn{4}{|c|}{ Education (age first left school) (trend test $P=0.0027$ ) } & Least disadvantaged & 268,943 & 265,850 & 49.7 \\
\hline $18+$ years & 29,843 & 7,488 & 53.3 & Less disadvantaged & 356,968 & 196,194 & 35.5 \\
\hline $15-17$ years & $1,015,223$ & 391,107 & 40.9 & Mid disadvantaged & 326,957 & 177,147 & 35.1 \\
\hline Under 15 years & 739,503 & 511,267 & 27.8 & More disadvantaged & 456,547 & 174,588 & 27.7 \\
\hline No schooling & 65,753 & 75,014 & 20.1 & Most disadvantaged & 436,269 & 169,649 & 28.0 \\
\hline \multicolumn{4}{|c|}{ Ethnicity (Usual language at home) ( $t$-test, English versus other, $P=0.8437$ ) } & \multicolumn{4}{|c|}{ Other adult in the household ( $t$-test, $P<0.0001$ ) } \\
\hline North European & 14,093 & 11,519 & 45.0 & Yes & $1,282,978$ & 729,105 & 36.2 \\
\hline EAsian & 7,750 & 5,380 & 41.0 & No & 567,344 & 255,771 & 31.1 \\
\hline SEAsian & 7,495 & 4,342 & 36.7 & & & & \\
\hline Eastern European & 39,580 & 21,713 & 35.4 & & & & \\
\hline English & $1,674,100$ & 889,696 & 34.7 & & & & \\
\hline South European & 91,186 & 47,442 & 34.2 & & & & \\
\hline All others & 16,118 & 4,785 & 22.9 & & & & \\
\hline
\end{tabular}

Use of pain relief for dental problems

The results showed a significant difference in attendance at dental services between those who had taken pain relief for dental problems: $82 \%$ had attended the dentist or dental professional in the previous year, compared with 35\% of those who had not taken any pain relief for dental problems. Any conclusions regarding pain relief should be tempered by the low numbers of respondents taking such medication.

\section{MULTIVARIABLE ANALYSIS}

The results from the logistic regression model are shown in Table 3 for males and Table 4 for females. Each variable is listed from lowest attendance to highest attendance and the odds ratio shows the odds of attending dental services between any one level and the lowest level.

\section{Males}

There were no significant interaction terms for males. Age, years of school, SEIFA index, exercise level, possession of a health concession card and smoking status were all significantly associated with a recent dental visit after adjustment for all other factors and interactions.

\section{Females}

For females, age, years of school, exercise level and smoking status were all significantly associated with a recent dental visit after adjustment for all other factors and interactions. While possession of a health concession card was the most significant factor to be introduced into the stepwise regression, that main effect was removed by the later introduction of a significant interaction between possession of a health card and locational disadvantage at the level of $P=0.0320$. The only significant individual interaction was between respondents from the two most socially disadvantaged areas, ie there was a significant increase in attendance between those with and without a health concession card between those from the most to the less disadvantaged areas.

\section{DISCUSSION}

This study has afforded an opportunity to investigate factors associated with dental visits in a population-based sample of the aged. The strength of this study includes the population-based nature of the data and consequent large number of respondents, even when limited to those, 60 years and over. The dataset considered here was a sample of non-institutionalised aged (hospitals, nursing and convalescent homes were excluded) with only those who did not know if they had visited a dentist being excluded. ${ }^{17}$ The data has extensive demographic and health behaviour information available for each respondent. The use of dental visit questions in such a National Health Survey was extremely useful. However, the study is also limited by the use of a national health survey where the authors cannot select the variables for which data was collected. The data also does not include any form of dental examination (although that would be of very high cost at population level). A number of salient points have emerged from this work. There 


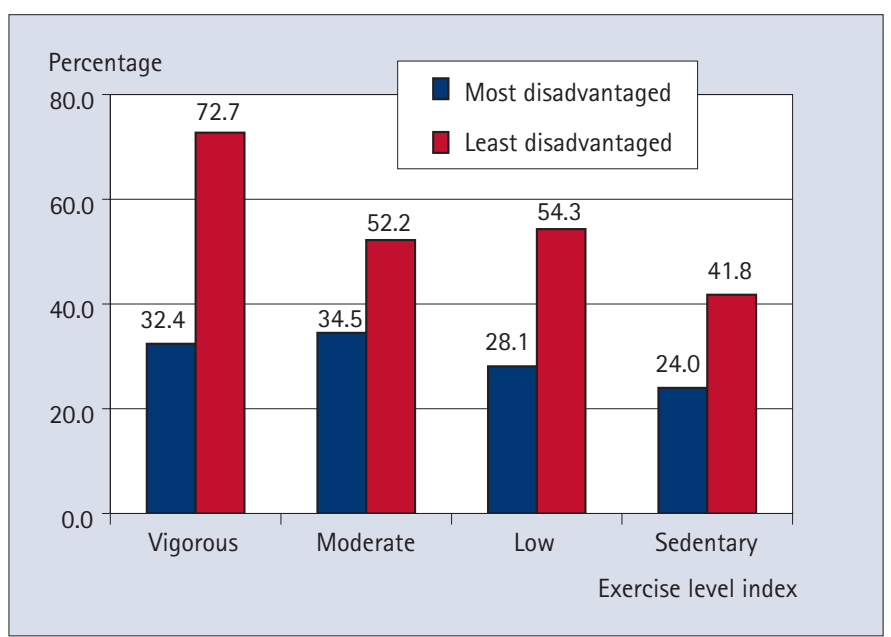

Fig. 2 Percentage of respondents who reported that they had seen a dentist or dental professional in the previous year by level of exercise and level of social disadvantage (weighted data)

was a clear relationship between the percentage of respondents attending dental services in the previous year and their reported level of social disadvantage and equivalent income deciles. The availability of subsidised treatment for some of those on a pension was not sufficient financial support to influence the level of attendance at dental services, with those people on a pension attending dental services less than those not on a pension. Those with private ancillary health insurance were more likely to have attended dental services in the previous year than those with no insurance. Possession of a health concession card reduced the percentage attending dental services. There was a strong positive relationship between years of schooling and attendance at dental services.

In this population-based study, men in this age cohort were more likely than women to have attended dental services in the

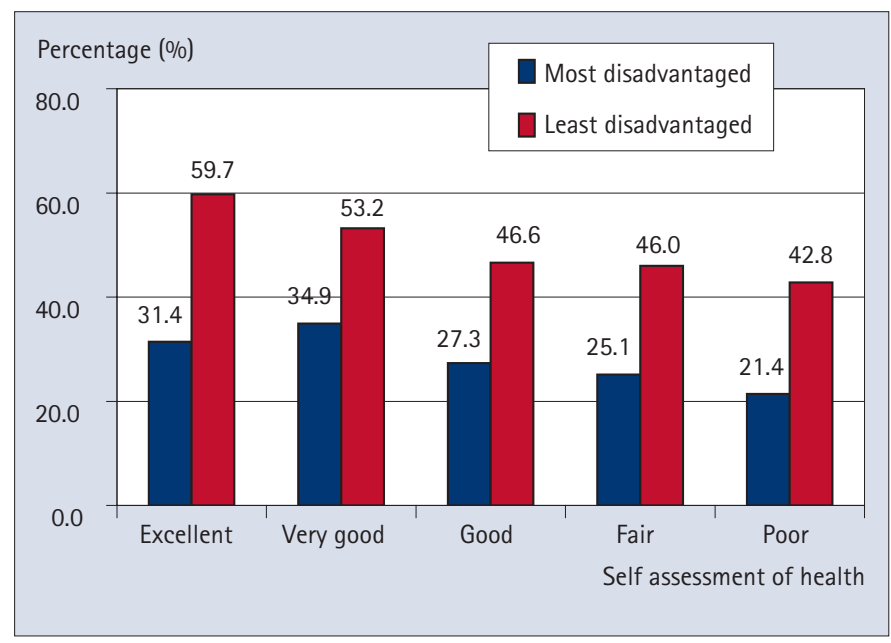

Fig. 3 Percentage of respondents within each level of social disadvantage and level of self-assessed health who reported that they had seen a dentist or dental professional in the previous year. (weighted data)

previous year. This differs from some other studies, for example Manski found little difference in dental visits by gender after excluding those that were edentate. ${ }^{9}$ However, others point out that there is dental need in all aged, regardless of dentate status. ${ }^{8}$ Both the males and the females were more likely to have attended a dental service in the previous year if they had another adult living in the household.

Those who reported excellent or very good health were more likely to have attended dental services than those who report their health as poor. Those who currently smoked were significantly less likely to have attended dental services in the previous year than those who were ex-smokers or did not smoke. Those undertaking vigorous exercise were more likely to have attended dental services in the previous year than those who were sedentary. It was

Table 2 Distribution of the number and percentage of respondents who had consulted a dentist or dental professional within the previous year for health insurance, health promotion and personal health related factors (weighted values)

\begin{tabular}{|c|c|c|c|c|c|c|c|}
\hline & $\begin{array}{c}\text { Number not } \\
\text { attending }\end{array}$ & $\begin{array}{l}\text { Number } \\
\text { attending }\end{array}$ & $\begin{array}{c}\text { Per cent } \\
\text { attending }\end{array}$ & & $\begin{array}{c}\text { Number not } \\
\text { attending }\end{array}$ & $\begin{array}{l}\text { Number } \\
\text { attending }\end{array}$ & $\begin{array}{c}\text { Per cent } \\
\text { attending }\end{array}$ \\
\hline \multirow[t]{2}{*}{ Health Insurance: } & & & & Moderate & 429,676 & 295,595 & 40.8 \\
\hline & & & & Low & 532,540 & 326,862 & 38.0 \\
\hline \multicolumn{4}{|c|}{ Private health insurance ( $t$-test, ancillary versus other, $P<0.0001)$} & Sedentary & 860,052 & 336,744 & 28.1 \\
\hline Ancillary only & 9,322 & 12,202 & 56.7 & & & & \\
\hline Hospital cover with ancillary & 195,651 & 200,674 & 50.6 & Personal hec & & & \\
\hline Hospital cover only & 117,984 & 64,184 & 35.2 & & & & \\
\hline \multirow[t]{2}{*}{ None } & 593,206 & 220,977 & 27.1 & Self-assessn & test,$P=0.00$ & & \\
\hline & & & & Excellent & 188,893 & 121,089 & 39.1 \\
\hline \multicolumn{4}{|c|}{ Health concession card ( $t$-test, $P<0.0001)$} & Very good & 411,152 & 264,035 & 39.1 \\
\hline No card & 306,704 & 293,157 & 48.9 & Good & 571,177 & 313,589 & 35.4 \\
\hline \multirow[t]{2}{*}{ DSS or DVA card } & $1,539,593$ & 690,722 & 31.0 & Fair & 461,004 & 206,157 & 30.9 \\
\hline & & & & Poor & 218,096 & 80,007 & 26.8 \\
\hline \multicolumn{8}{|l|}{ Health promotion: } \\
\hline & & & & \multicolumn{4}{|c|}{ Presence of arthritis ( $t$-test, $P=0.8942$ ) } \\
\hline \multicolumn{4}{|c|}{ Smoking status (trend test, $P=0.5660$ ) } & Yes & 758,017 & 404,771 & 34.8 \\
\hline Ex-smoker & 672,345 & 394,779 & 37.0 & No & $1,092,305$ & 580,105 & 34.7 \\
\hline Never smoked & 900,512 & 497,616 & 35.6 & & & & \\
\hline \multirow[t]{2}{*}{ Current smoker } & 277,465 & 92,481 & 25.0 & Use of pain $r$ & $t$-test, $P<0.0$ & & \\
\hline & & & & Yes & 1,035 & 4,767 & 76.5 \\
\hline \multicolumn{4}{|c|}{ Exercise level index (trend test, $P=0.0397$ ) } & No & $1,849,288$ & 980,109 & 35.3 \\
\hline Vigorous & 28,054 & 25,675 & 47.8 & & & & \\
\hline
\end{tabular}




\begin{tabular}{|c|c|c|c|c|}
\hline Males & OR & Lower $\mathrm{Cl}$ & Upper Cl & $P$ \\
\hline Age & & & & $<0.0001$ \\
\hline $80+$ & 1.00 & & & \\
\hline $75-79$ & 1.81 & 1.33 & 2.49 & \\
\hline 70-74 & 2.22 & 1.67 & 2.96 & \\
\hline $65-69$ & 1.70 & 1.28 & 2.26 & \\
\hline $60-64$ & 1.66 & 1.24 & 2.24 & \\
\hline Years at school & & & & $<0.0001$ \\
\hline No schooling & 1.00 & & & \\
\hline Under 15 years & 0.74 & 0.34 & 1.62 & \\
\hline $15-17$ years & 1.12 & 0.51 & 2.54 & \\
\hline $18+$ years & 1.50 & 0.67 & 3.52 & \\
\hline Locational disadvantage & & & & $<0.0001$ \\
\hline Most disadvantaged & 1.00 & & & \\
\hline More disadvantaged & 0.84 & 0.67 & 1.06 & \\
\hline Mid disadvantaged & 1.03 & 0.81 & 1.30 & \\
\hline Less disadvantaged & 1.07 & 0.85 & 1.35 & \\
\hline Least disadvantaged & 1.66 & 1.32 & 2.08 & \\
\hline Exercise & & & & $<0.0001$ \\
\hline Sedentary & 1.00 & & & \\
\hline Low & 1.34 & 1.12 & 1.61 & \\
\hline Moderate & 1.43 & 1.20 & 1.70 & \\
\hline Vigorous & 2.16 & 1.38 & 3.38 & \\
\hline \multicolumn{5}{|l|}{ Health concession card } \\
\hline Has a card & 1.00 & & & \\
\hline No card & 1.33 & 1.10 & 1.60 & 0.0018 \\
\hline \multicolumn{5}{|l|}{ Smoking status } \\
\hline Current smoker & 1.00 & & & \\
\hline Not a current smoker & 1.77 & 1.43 & 2.18 & $<0.0001$ \\
\hline
\end{tabular}

potentially concerning that those who took medication for dental pain were less likely to have visited a dentist if they lived in lower socio-economic areas.

The primary conclusion of this analysis is that attendance at dental services is associated with age, years of schooling and the availability of resources to pay for treatment. Oral health promotion activities could be directed to current smokers who have a low attendance profile.

Analysis of the level of social disadvantage and dental visits using the SEIFA Index of relative socio-economic disadvantage determined in quintiles, uptake of private health insurance and the possession of a health card indicated a lack of equity of use which indicated that not enough was being done to ensure all Australians use appropriate dental services. However, the relationship between access and use may not be straightforward. Those with access to appropriate services still may not use these services. It is also important to note that SEIFA is based on the local area measure rather than the individual level and interpretation as an individual measure may risk ecological fallacy, although the value of area based social contexts has also been recognised. ${ }^{23}$ The role of area factors versus individual factors in the use of dental services warrants further investigation, for example those living in an area with higher average income may have a different use of dental services than those in a poorer area even when individual factors are accounted for. Given that there was additional federal funding for dental services for disadvantaged adults in Australia from 1994 to 1996, the impact of disadvantage on dental visits may have been reduced during this time increasing the importance of these findings. ${ }^{13}$

This study demonstrates very clear trends in the use of dental services in those aged 60 years and over. These need to be addressed by ensuring access to services for the more disadvantaged elderly. In addition, resources allocated to increasing prevention in earlier years will assist in reducing the growing burden on dental services in the aged.

In memory of Dr Jilda Hyndman, a gifted epidemiologist and valued colleague.

The authors would like to thank David Lawrence and Max Bulsara for advice on statistics and the use of the National Health Survey data. The Australian Bureau of Statistics supplied the data but they are not responsible for the analysis. The research was funded by the Cottesloe Bequest through The Faculty of Medicine and Dentistry, The University of Western Australia.

1 Bradnock $G$, Pine $C M$. Delivery of oral health care and implications for future planning: In:Pine C M. (ed) Community Oral Health. Wright: Oxford, 1997. 2 Department of Health and Human Services Oral Health in America. A report of the Surgeon-General 2000. Rocksville, MD: US Department of Health and Human Services. 3 Brown R H, Treasure E T. Inequalities in oral health: implications for the delivery of 


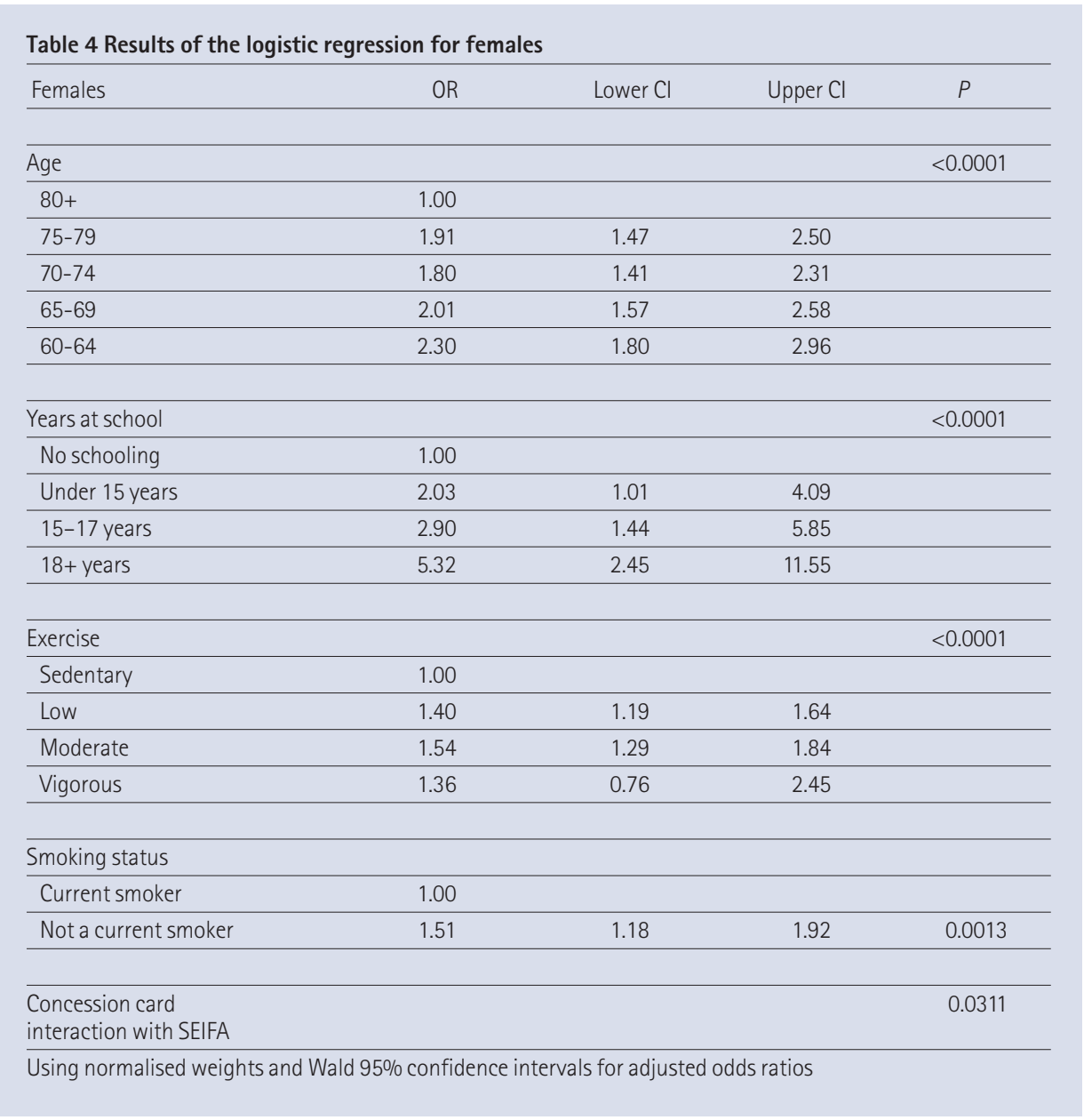

care and health promotion. NZDent J 1992; 88: 132-138.

4 Chen M S. Hunter P. Oral health and quality of life in New Zealand: A social perspective. Soc Sci Med 1996: 8: 1213-1222.

5 Ettinger R L. Oral disease and its effect on the quality of life. Gerodontics 1987; 3: 103-106.

6 McGrath C, Bedi R. The importance of oral health to older people's quality of life. Gerodontology 1999; 16: 60-63.

7 Dixon G S, Thomson W M, Kruger E. The West Coast Study. I: self-reported dental health and the use of dental services. NZDent J1999; 95: 38-43.

8 Wilson $A$ A, Branch $L$ G. Factors affecting dental utilization of elders aged 75 years or older. J Dent Educ 1986; 50: 673-667.

9 Manski R J. Variable confounding and the influence of non-economic determinants on dental utilization for the elderly. Maryland State Dent Assoc J 1995; 38: 171-174.

10 Australian Institute of Health and Welfare. Australia's Health 2000. Australian Government Publishing Service, Canberra.

11 Roberts-Thomson. Social inequality in the use and comprehensiveness of dental services. Aust J Public Health 1995; 19: 80-85.

12 Senate Committee Hansard. Community affairs reference committee: Public dental services. Canberra: Commonwealth of Australia, 1998.

13 Dooland M. National health strategy: Improving dental health in Australia. Background paper No 9. Canberra, 1992.

14 Brennan DS, Carter K D, Stewart J F, Spencer A J. Commonwealth dental health program evaluation report 1994-1996. AlHW Dental Statistics and Research Unit, The
University of Adelaide, Adelaide, 1997.

15 Manski R J, Moeller J F, Maas W R. Dental services. An analysis of utilization over 20 years. JAm Dent Assoc 2001; 132: 655-664.

16 Slade G D, Spencer A J, Gorkic E, Andrews G. Oral health status and treatment needs of non-institutionalised persons aged 60+ in Adelaide, South Australia. Aust Dent J 1993; 38: 373-380.

17 Australian Bureau of Statistics. 1995 National Health Survey users' quide. Cat no 4363.0 Canberra: Australian Bureau of Statistics, 1996.

18 Australian Bureau of Statistics. 1996 Census of population and housing - basic community profile. Catalogue No. 2019.5.30.001. Australian Bureau of Statistics, Canberra, 1999.

19 Carter K D, Brennan D S, Stewart J F. Adult access to dental care: migrants. Australian Institute of Health and Welfare Dental Statistics and Research. Series No 15, 1998; The University of Adelaide, Adelaide.

20 Australian Bureau of Statistics 1991 Census of population and housing - basic community profile. Catalogue No. 2722.5. Australian Bureau of Statistics, Canberra, 1993.

21 Ware J E, Korinski M, Keller S D. SF-36 Physical and mental health summary scales: a user's manual. Boston, MA: The Health Institute, 1994.

22 Statistical Analysis System Version 8.2. Statistical Institute Inc, SAS System, Cary, NC 2001.

23 Blakely TA, Woodward A J. Ecological effects in multi-level studies.[comment]. J Epidemiol Community Health 2000; 54:367-374. 